\title{
The Fertility Increase in Finland in 1982
}

\author{
JARL LINDGREN
}

Research Associate

The Population Research Institute

Changes in external conditions have always affected fertility. In preindustrial times good and bad harvests, wars and famines left their traces in fertility development. Even in industrialized society dependence on the external milieu is visible, if not as drastically as in old times.

In the old society the family's immediate living environment regulated fertility more or less directly through death and diseases. Nowadays not only the local environment but also national conditions and even international events affect the families' decisions to have children and when to have them. Families have access to effective birth control methods and they could rapidly react to the changing environment. On the other hand, structural changes and business fluctuations usually do not strike the whole population at the same time.

At the end of 1981 fertility began to increase in Finland and continued on a somewhat higher level during the whole following year and at least during the first half of 1983. This fertility increase occurred quite unexpectedly and the first estimates told of a considerable augmentation. The final number of children born in 1982 was, however, less than the first estimate; the increase was only six percent.

As fertility development has always been followed with interest in Finland, newspapers and magazines eagerly debated the reason for this sudden growth. Various guesses and assumptions were brought forth.

Although the increase was rather small, it seems to be of some interest to examine the structure of the fertility rise. The following is an attempt to analyze the characteristics of the increase in 1982 according to the age of the mother, the mother's income, and parity.

In 1982 the total number of live births was $67000^{1}$ according to the preliminary data, and in 1981, 63469 (OSF 1983). The total fertility rate in 1980 and 1981 was practically the same or 1.634 and 1.638 per woman (OSF 1983). In 1982 it rose to 1.744 .

1 When this article was written in the beginning of 1984 , the exact number of live births was not yet known. 
Figure 1 shows the monthly general fertility rate of 15 - to 44 -year-old females calculated by using the quarterly mean population of females nine months prior to confinement. The figure indicates that throughout 1982 fertility was higher than in $1981 .{ }^{2}$

F i g u r e 1. The general fertility rate of 15-44-year-olds in 1981 and 1982 .

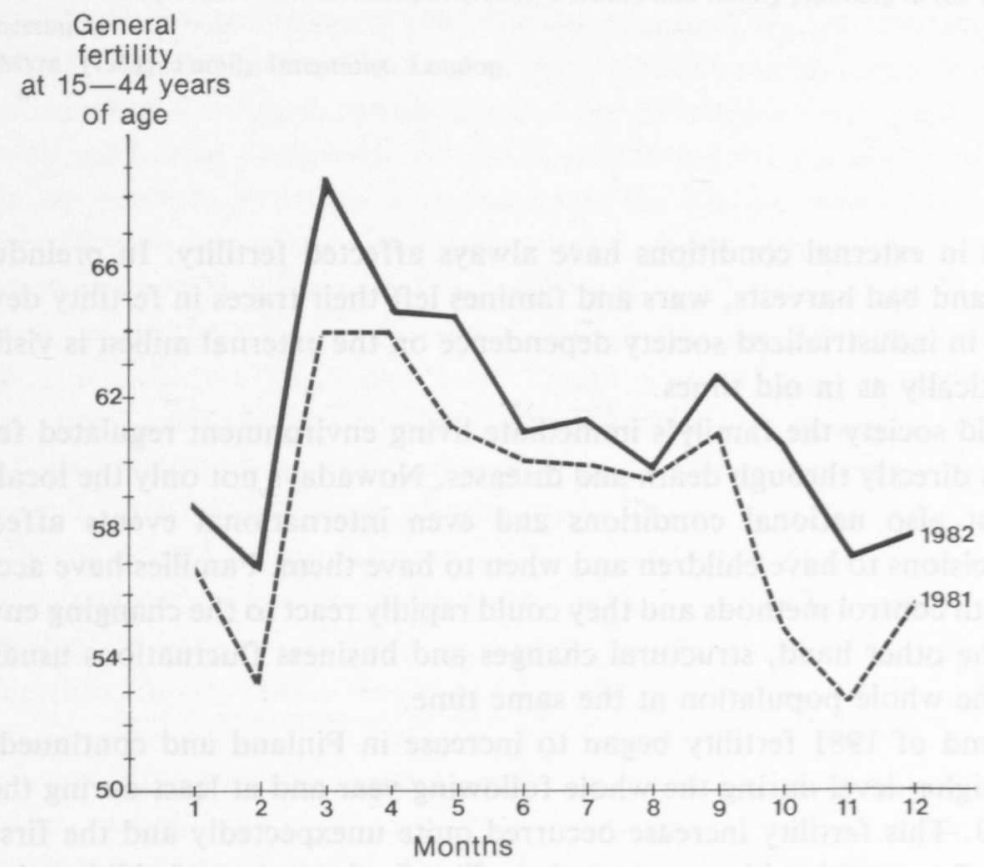

\section{Fertility and income}

The fertility increase was said to have originated in the upper income classes. One reason mentioned was the change in the maternal allowance which from the beginning of 1982 was related to wages. Mothers in upper income groups, especially, benefited from this amelioration.

On the whole, this study confirms what had been commonly observed; fertility showed the most significant increase in the uppermost income group. The number of children born within this income group was more than twice as many as in 1981 . Proportionally the increase was still greater (Table 1).

${ }^{2}$ For the data used in this article I am indebted to Mr. Markku Ryynänen, The Social Insurance Institution. 
T a b l e 1. Live births according to income groups in 1981 and 1982 .

$\begin{array}{cccccc} & 0 & 1-20599 & 20600-49999 & 50000- & \text { Unknown } \\ 1981 & \% & \% & \% & \% & \% \\ 1982 & 19.0 & 43.5 & 34.1 & 3.3 & 1.2 \\ & 11.1 & 29.0 & 52.0 & 7.9 & 1.1\end{array}$

Even in the intermediate income group fertility increased but somewhat less: it was about half as large as during the preceding year. In the lowest income group and among those with no income, fertility, on the contrary, was smaller than in 1981.

A closer analysis of the uppermost income group shows that proportionally the most important increase was found among those with the highest income.

Income is comprised in both years of wages and salaries earned by mothers in $1981 .^{3}$ A more feasible basis would possibly have been the income of both parents. As, however, the maternity allowance during maternity leave is based on the mother's wages, it was considered most meaningful to use her income. ${ }^{4}$

The income groups used here are the same in 1981 and 1982. It is not likely however, that any significant changes have occurred in the structure of the income groups during this time. As a consequence of the depreciation in monetary value, however, incomes have risen from 1981 to 1982 an average of 10 percent (CSO 1982, Table 297). The impact of this change in monetary value is that the uppermost income group in 1982 is somewhat larger compared with 1981, and correspondingly the lowest income group is somewhat smaller. Its possible effect on the pattern of the increase has not been more closely analyzed.

It does not seem likely that the ameliorated maternal allowance affected fertility, at least not to any larger extent. If the improved allowance would have influenced fertility, couples would have had to have taken the greater allowance into consideration more than half a year before it came in force, which seems rather unlikely. On the whole, the significance of the mother's allowance on the decision to have children seems to be rather small as was also shown by a survey made in 1983 among the readers of a family magazine: only one tenth of the responses mentioned the improved allowance as a reason affecting the decision to have a child (Hatunen $1984,100)$. This proportion is probably also somewhat exaggerated as couples with a higher education were overrepresented among the respondents.

It is more likely that the reason for the increased fertility was a consequence of more births among the large age groups born after the Second World War. It has

\footnotetext{
${ }_{3}^{3}$ The corresponding distribution into income groups in 1982 was not yet known when this article was written.

${ }^{4}$ Here only three income groups have been used besides those with no income. Hence they give only a rough picture of the division of mothers into income groups. Unfortunately it has not been possible to determine the relative size of income groups, as the total number of females belonging to these income groups is not known.
} 
always been supposed that they have postponed having children because of difficulties in obtaining vocational training, dwellings and jobs. These age groups were now at the age of $30-35$ years, at the age when couples in modern society generally stop having babies.

\section{Fertility at different ages}

Newspapers in 1982 also stated that there were more older pregnant women on the streets than during earlier years.

The age-specific fertility rates, however, show that fertility had increased more or less in all age groups (Table 2). The increase was proportionally most obvious among those aged $40-45$ years, or 16 percent. In the most fertile age groups, i.e. women $25-34$ years of age, the increase was $6-7$ percent. The absolute increase in the last mentioned age groups was, of course, much more important than in the $40-45$-year age group.

T a b l e 2. Age-specific fertility rates in 1981 and 1982.

$\begin{array}{lrrc} & 1982 & \begin{array}{c}\text { Increase } \\ \text { Decrease } \\ \%\end{array} \\ 15-19 & 1981 & \\ 20-24 & 16.9 & 16.4 & -3.0 \\ 25-29 & 88.7 & 90.5 & +2.0 \\ 30-34 & 118.3 & 125.1 & +5.7 \\ 35-39 & 69.8 & 74.5 & +6.7 \\ 40-44 & 29.8 & 30.4 & +2.0 \\ 45-49 & 6.1 & 7.1 & +16.4 \\ & 0.4 & 0.4 & \pm 0 \\ \text { OSF VI A: } 146, \text { Table 53. } & & \end{array}$

The changes in age structure had a rather small effect on the increase. Compared with 1981 the mean number of females 20 to 34 years of age in 1982 had decreased less than one percent. The age group 35-39 years, on the contrary, showed an increase which approaches seven percent. The following age group, 40-44 years of age decreased by five percent. Consequently, it was only in the age group 35-39 years where we could have expected a small increase of children.

The assumption that the increase was most important in the uppermost income group among older age groups is also supported by the statistics. Already Table 1 indicated that fertility diminished in the lowest income group. 
When examining the age groups splitted into income groups a distinct pattern seems to be visible (Table 3). Firstly, the births are proportionally fewer in all age groups among mothers with no income and those belonging to the lowest income groups (0-20 599 FIM). Secondly, the difference decreased toward older age groups. The largest difference was found in the highest income group.

$\mathrm{T}$ a b l e 3. The proportional distribution of live births according to income and age.

\begin{tabular}{rrrrrrrrrrrr} 
& & & \multicolumn{1}{c}{$1-20559$} & \multicolumn{2}{c}{$20000-$} & \multicolumn{2}{c}{$50000-$} & \multicolumn{2}{c}{ N } \\
& & & \multicolumn{2}{c}{ FIM } & \multicolumn{2}{c}{49 999 FIM } & \multicolumn{2}{c}{ FIM } \\
& 1981 & 1982 & 1981 & 1982 & 1981 & 1982 & 1981 & 1982 & 1981 & 1982 \\
$20-24$ & 21.4 & 10.5 & 54.6 & 40.4 & 23.8 & 48.4 & 0.2 & 0.6 & 16068 & 16330 \\
$25-29$ & 16.6 & 9.4 & 42.1 & 23.9 & 38.6 & 60.0 & 2.6 & 6.6 & 22984 & 23976 \\
$30-34$ & 16.6 & 11.5 & 35.4 & 24.0 & 41.9 & 53.4 & 6.1 & 14.0 & 14799 & 15369 \\
$35-39$ & 17.8 & 13.2 & 32.3 & 21.0 & 41.0 & 46.3 & 8.8 & 19.4 & 4949 & 5543 \\
$40-44$ & 19.3 & 15.5 & 35.6 & 23.4 & 34.6 & 40.9 & 10.4 & 20.2 & 881 & 1020
\end{tabular}

\section{Fertility and parity}

In the fertility increase emanated from the large cohorts born after the World War one would expect more children of higher parity. It is likely that most of the couples belonging to these cohorts have generally had at least their first child. And examination of the fertility increase according to parity shows that the distribution of birth order was almost the same during both years. Fourth child, however, displayed a more distinct increase or ten percent. Third child showed an increase of five percent (Table 4).

$\mathrm{T}$ a b l e 4. Live births according to parity in 1981 and 1982 .

$\begin{array}{cccccc} & \text { 1st Child } & \text { 2nd Child } & \text { 3rd Child } & \text { 4th Child } & \text { 5th Child } \\ 1981 & 42.8 & 37.8 & 13.9 & 3.1 & 2.3 \\ 1982 & 42.3 & 37.5 & 14.6 & 3.4 & 2.1\end{array}$

In the lowest income group as well as among those with no income, fertility in all parities was smaller in 1982 than in 1981 (Table 5). Most accentuated was the difference among those having their first and second child.

In the intermediate and uppermost income group the difference was the opposite. Further, the increase was most obvious for the first child and decreases towards higher parity. The statistics do not seem to support the assumption that the increase was mainly caused by an increase of children of higher birth orders. 
$\mathrm{T} \mathrm{a} \mathrm{b} \mathrm{l} \mathrm{e} \mathrm{5.} \mathrm{The} \mathrm{proportion} \mathrm{of} \mathrm{live} \mathrm{births} \mathrm{according} \mathrm{to} \mathrm{parity} \mathrm{and} \mathrm{income.}$

\begin{tabular}{|c|c|c|c|c|c|c|c|c|c|c|}
\hline & \multicolumn{2}{|c|}{0} & \multicolumn{2}{|c|}{$1-20599$} & \multicolumn{2}{|c|}{$\begin{array}{r}20600- \\
49999\end{array}$} & \multicolumn{2}{|c|}{$50000-$} & \multicolumn{2}{|c|}{$\mathrm{N}$} \\
\hline & 1981 & 1982 & 1981 & 1982 & 1981 & 1982 & 1981 & 1982 & 1981 & 1982 \\
\hline 1st Child & 12.4 & 4.4 & 46.6 & 26.7 & 36.2 & 59.3 & 3.0 & 8.1 & 26843 & 28029 \\
\hline 2nd Child & 19.3 & 11.6 & 41.3 & 28.4 & 35.0 & 50.9 & 3.2 & 7.6 & 23706 & 24791 \\
\hline 3rd Child & 27.5 & 18.9 & 38.5 & 32.5 & 28.5 & 39.8 & 4.1 & 7.6 & 8712 & 9673 \\
\hline 4th Child & 33.7 & 27.9 & 39.1 & 35.8 & 21.4 & 27.8 & 3.9 & 6.6 & 1943 & 2265 \\
\hline 5th Child & 53.4 & 47.0 & 30.3 & 32.7 & 11.9 & 13.7 & 2.7 & 4.9 & 1450 & 1447 \\
\hline
\end{tabular}

\section{Conclusions}

The examination of the increase shows that it was almost totally caused by a rise in fertility rates. Only approximately one tenth emanated from a change in the age distribution.

A typical feature of the increase was the concentration of births toward the uppermost income group where the fertility rise was visible in all parities. At the same time a decrease was discernable in lower income groups. Further, a tendency toward more births in older age groups was verified. The assumption that the increase in absolute terms should have been caused by births of higher parity could not be proved. The absolute increase was approximately the same among those having their first to third child. Proportionally, the increase in fourth child was highest.

On the whole, one could speak of a tendency to higher birth rates in upper income classes, in higher parities and in older age groups. Nevertheless, the fertility increase in 1982 must be considered a more or less general phenomenon. The increase in number was highest in the younger, most fertile, age groups but rather high also in lower parities spread over all age groups.

As has often been proved, it is almost impossible to determine the reasons behind the fertility waves in the industrial low-fertility countries. One reason is perhaps that, simultaneously and in different ways, several incitements are affecting families at different stages of the family cycle. Young and old families seem to experience society differently. Old couples who have already established their place in society do not seem to feel insecurity and uncertainty concerning the future as strongly as younger people probably do.

It does not seem likely that an upward trend in the economic situation would have been behind the increase. In the beginning of 1981 the GNP showed an increasing tendency which, however, turned downward again at the end of the year. Also, the unemployment rate increased in 1981. Most likely the increase was the result of several factors affecting the families' decisions to have children. The difficulty in pointing out the main reason for the increase is probably that there is no main reason and that the effect of a particular factor in itself is negligible. 


\section{References}

CSO (Central Statistical Office of Finland). (1983). Statistical Yearbook of Finland 1982. Helsinki. Hatunen, Hellevi. (1984). Miksi vauva juuri nyt? »Halusimme saada lapsia perheeseen». Kaks'plus. No. 2, pp. 99-101. Tampere.

OSF (Official Statistics of Finland) VI A:146. (1983) Population 1981. Volume I. Central Statistical Office of Finland. Helsinki. 